Revista de la red interuniversitaria de estudios sobre las literaturas rioplatenses contemporáneas en Francia

$22 \mid 2021$

¿Cómo se cuenta una vida? El retorno de lo biográfico en la literatura rioplatense contemporánea

\title{
Qué intenso puede ser el instante. La escritura del yo en Alejandro Rubio y Silvio Mattoni
}

Comme l'instant peut être intense. L'écriture du moi dans Alejandro Rubio et Silvio Mattoni

How intense the instant can be. The writing of the self in Alejandro Rubio and Silvio Mattoni

\section{Anahí Mallol}

\section{OpenEdition}

\section{Journals}

Edición electrónica

URL: http://journals.openedition.org/lirico/10776

DOI: $10.4000 /$ lirico. 10776

ISSN: 2262-8339

Editor

Réseau interuniversitaire d'étude des littératures contemporaines du Río de la Plata

Referencia electrónica

Anahí Mallol, «Qué intenso puede ser el instante. La escritura del yo en Alejandro Rubio y Silvio Mattoni», Cuadernos LIRICO [En línea], 22 | 2021, Publicado el 11 marzo 2021, consultado el 16 marzo 2021. URL: http://journals.openedition.org/lirico/10776 ; DOl: https://doi.org/10.4000/lirico.10776

Este documento fue generado automáticamente el 16 marzo 2021.

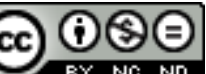

Cuadernos LIRICO está distribuido bajo una Licencia Creative Commons Atribución-NoComercialSinDerivar 4.0 Internacional. 


\section{Qué intenso puede ser el instante. La escritura del yo en Alejandro Rubio y Silvio Mattoni}

Comme l'instant peut être intense. L'écriture du moi dans Alejandro Rubio et Silvio Mattoni

How intense the instant can be. The writing of the self in Alejandro Rubio and Silvio Mattoni

Anahí Mallol

\section{Introducción}

1 Las escrituras del yo, al no poseer la sólida justificación literaria de que gozan otros géneros (Loureiro 1991), plantean desde el inicio algunas preguntas ${ }^{1}$ : ¿por qué se escribe un diario, o una autobiografía?, ¿desde qué lugar se escriben y se leen?, ¿como modo de hacer público lo privado o para dar cuenta de unos acontecimientos, de unos pensamientos, de una deriva afectiva?, ¿para justificarlos o justificarse?, ¿como cifra o medida de algo?, ¿porque se es interesante, o se asistió a acontecimientos importantes? ¿o por todo lo contrario?

2 Y está como cuestión central, aquella con la que Alejandra Pizarnik hizo casi un aforismo, cuando escribió en su diario el 15 de abril de 1961: "La vida perdida para la literatura por culpa de la literatura. Quiero decir, por querer hacer de mí un personaje literario en la vida real, fracaso en mi deseo de hacer literatura con mi vida real, pues ésta no existe; es literatura" (2003: 200) y en los versos finales de "El deseo de la palabra", último poema de su último libro publicado en vida, El infierno musical: "Ojalá pudiera vivir solamente en éxtasis, haciendo el cuerpo del poema con mi cuerpo, rescatando cada frase con mis días y con mis semanas, infundiéndole al poema mi soplo a medida que cada letra de cada palabra haya sido sacrificada en las ceremonias del vivir" (1994: 175). 
3 Marcaba Pizarnik, de manera exasperada, una aporía entre vida y letra, en la que la vida se perdía por la letra y la letra se perdía por la vida. Y Lacan (2008) por los mismos años señalaba estos puntos de imposible decisión como momentos de crisis del sujeto, en su trabajo sobre la disyuntiva entre "la bolsa o la vida". El apócrifo poema de Borges intentaba dar una respuesta previsible (a la vez inverosímil) a esta cuestión que pretendía, en su apelación al sentido común, destruir las bases de su estética. Mientras que el Borges auténtico encomiaba la vida literaria, la vida en y por la literatura y el mundo como biblioteca (Pastormerlo 2007), decía el Borges apócrifo:

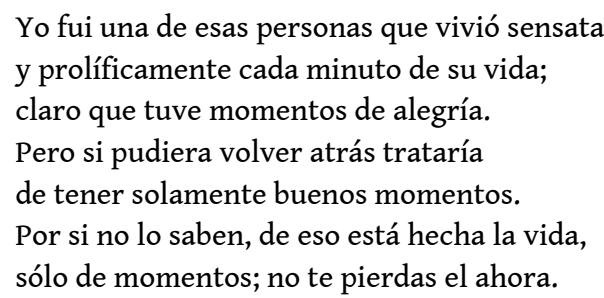

4 Respecto de las aporías de la decisión imposible Jacques Lacan trabaja en el Seminario 11 la perspectiva lógica y su efecto de alienación subjetiva, producida por el intento vano de querer conservar ambas partes de la ecuación, en tanto "la elección sólo consiste en saber si uno se propone conservar una de las partes, ya que la otra desaparece de todas formas" (2008: 219). Introduce la disyuntiva de la elección forzada en la ética del deseo, mediante el ejemplo del sujeto que, bajo amenaza, debe elegir: “iLa bolsa o la vida!”: si elige quedarse con la bolsa, perderá la vida y, con ella, también la bolsa; si elige quedarse con la vida, quedará desprovisto de bolsa. Dado que para conservar la vida el sujeto tiene que pagar el precio de la pérdida de la bolsa, la elección forzada se ubica en un plano ético que implica admitir una única salida posible para defender un valor supremo. Esta estructura sitúa entonces un elemento fundamental a tener en cuenta cuando se habla de la vida, pero también de la literatura: la pérdida. La literatura trabaja justamente en el borde que impone esa conciencia: frente a lo pleno de la palabra imaginaria, la ley de lo literario, en el borde entre lo que se puede decir y lo que no, en la falla entre la palabra y la cosa, entro lo real y su nominación, impone su presencia en el escenario de la falta, es decir, evidencia la presencia de una ausencia.

5 Si ello es claro en los géneros de la ficción, no lo es tanto con los del yo, y la vía de la pérdida de la adecuación entre la palabra y la cosa como característica estructural del lenguaje lleva a pensar de una manera singular e interesante los géneros de la intimidad en cuestión, donde la falla se inscribe entre la palabra "yo" y un sujeto. Desde allí es posible volver a preguntar: ¿quién pierde y quién gana en la escritura? Y ¿qué pierde y qué gana en la escritura el escritor?

Por lo que respecta a las escrituras del $\mathrm{yo}^{2}$ se puede observar que hay textos que surgen como constatación de supervivencia, o, incluso, causa y modo de una supervivencia, diarios en que la constancia diaria de la escritura es un soporte vital, una contención frente a la locura o la angustia, o una salida simbólica de esa situación; son diarios en los que la letra sostiene la vida, aún en esos casos límite en que el acto de la escritura puede acarrear el riesgo de la vida. Pueden pensarse, entonces, como textos vitalistas, porque están del lado de la vida y lo viviente.

7 Hay textos que surgen desde la perspectiva de la muerte, porque se escriben como resguardo ante ese horizonte, o como espera de una muerte anunciada, o deseada, textos mortíferos. Son textos que dicen la muerte todo el tiempo, que hacen la muerte, como muchas de las entradas de Pizarnik. También puede ocurrir que surjan para 
construir desesperadamente una memoria que preserve la vida frente a la muerte, como permanencia póstuma o autojustificación de la propia vida allí donde lo autobiográfico "suele ser un conato de justificación, frente a tribunales más o menos imaginarios" (Panesi 1996: 66).

La economía autobiográfica en estos casos subrayaría ese precio absoluto, el de la muerte. "Y se trata, precisamente de eso. De la relación siempre general y siempre particular de lo escrito con la muerte que figura sin representarse en cualquier texto o género, pero que la literatura y en especial la autobiografía permitirían reconocer. Como si la autobiografía pusiera de manifiesto esa especie de acto fundamental de supervivencia que implica la repetición y la muerte" ${ }^{3}$. Ahí donde autobiografía es tanatografía, y paga el precio de la muerte, dice Panesi (1996: 67).

Están también los textos ${ }^{4} \mathrm{o}$, mejor, los escritores, conscientes de la inanidad del trabajo diario o autobiográfico, del carácter probablemente efímero de la escritura, y que, no obstante, escriben, o dejan que se escriba, sin plantar una posición ante disyuntivas como la bolsa y la vida, o la escritura y la vida. Diarios de cierta indiferencia, o diarios desencantados, que atraviesan la disyuntiva misma y la diluyen.

Para analizar más detalladamente las diferencias entre distintas opciones se puede pensar, por ejemplo, en la recopilación, hecha por el hijo, de los relatos orales de Joseph Minc, en La extraordinaria historia de mi vida ordinaria. El libro intenta reunir la memoria de una vida extraordinaria. Joseph Minc fue un judío polaco, militante del partido comunista, que sobrevivió como emigrado en París a la Segunda Guerra Mundial, primero unido a las fuerzas polacas, después a la Resistencia. Se retiró del Partido, desilusionado, en los inicios de los 70. Su intención es "contar mi vida, y los recuerdos de esa época fuera de lo común que me tocó vivir" (2009: 11). Piensa, en primera instancia, en transmitir a su familia los avatares de una existencia singular. Pero su hijo, quien firma el prefacio y que aparece como promotor del trabajo de escritura (para cuya realización contrató a un profesional que ayudara a "dar forma" a esos recuerdos), subraya como un deber la tarea de preservar la memoria, "porque la desaparición de los mundos que recordaba mi padre es más rápida de lo que creemos y porque no hay razones (...) para "privatizar" ese testimonio" (9). El valor del texto es ejemplar, no porque retrate a un héroe, sino porque es producto de una posición intelectual y ética ante los acontecimientos históricos. Si el libro evoca, en su inicio, el judaísmo anterior al exterminio, y el comunismo en su mejor momento, y la caída de ambos, trenzado en la vida de un ser humano común, el contraste entre la guerra y la paz, las dificultades extremas y la trivialidad de la vida posterior, busca respuestas a preguntas fundamentales, y es la base de un pensamiento crítico ("evitó que me convirtiera, a pesar de las apariencias, en un burgués de esos que al elitismo republicano le encanta producir" (9), dice Alain Minc).

Lo que importa en este caso no es la textura de la obra, sino la pregnancia de los acontecimientos narrados (Loureiro 1991), por lo cual, más allá de los detalles, está llevado por una pulsión realista. Apela, entonces, a la curiosidad del lector, a su avidez por conocer detalles de una época, una situación política y social, un estilo de supervivencia. La idea de escritura literaria puede estar todo lo lejos que se quiera: ello no altera el valor del texto.

12 Hay infinitos libros como éste, cada uno lleva la marca de su singularidad, y es una parte de un abanico que cubre una época, unos sucesos, sin colmarla jamás. En este caso, especialmente, lo crucial, la propuesta de fondo, es mostrar, contrapuesta a la 
banalidad del mal, la dimensión extraordinaria, o heroica, que puede tomar la vida de un ser humano común, en unas circunstancias extremas, y encarna una ética histórica (Ricoeur 2006).

13 Cuando los textos no conllevan esa dimensión narrativa histórica se suscitan otras cuestiones. Hay textos que se leen por el interés que provocan sus autores: escritores que han descollado en otros géneros, cuya cotidianidad, gustos, secretos de vida y escritura, producen curiosidad, como los diarios de Kafka o Pizarnik, de Mansfield, y tantos otros, textos en los que el pacto autobiográfico, en términos de Lejeune (1991) implicaría, además de la identidad entre autor, narrador y personaje principal, la identidad con el autor de otros textos relevantes ${ }^{5}$.

Entonces, es la firma de los textos otros la que estaría justificando la publicación (tal vez no la escritura) de los textos en este género: una huella que ya se dejó en otro lado, una firma que permea lo que es posible decir en este. A su vez, esto instala la cuestión de las relaciones entre el otro género y el género íntimo, de las maneras más diversas ${ }^{6}$.

Pero están también los diaristas puros, los que no escriben sino el diario. Allí la pregunta por la justificación textual se hace más acuciante, si la empresa no responde a un plan o tarea específicos (como diario espiritual o psicológico, diario de escritor que se escribe en situación de "bloqueo" respecto del género mayor, o como reservorio de motivos literarios a usar a posteriori), a la vez que resalta una apuesta estética cara a la contemporaneidad, que explora la futilidad, la intrascendencia, como posición privilegiada de enunciación.

\section{Las escrituras del yo en dos poetas argentinos de los 90}

\section{Alejandro Rubio}

En la Autobiografía podrida (2010) de Alejandro Rubio nos encontramos con una autobiografía en el sentido fuerte: una justificación de la vida, que lo es también de la escritura. El relato elige unas pocas situaciones o momentos para articular la narración de la vida como sucesión de momentos definitorios, y esta elección va de los puntos iniciales habituales de toda autobiografía (nacimiento, formación) a los elementos que conformarían una "vida de escritor" en su época: sexualidad, drogas, talleres de escritura, relación con un maestro y con los pares, política. Más allá de que casi todos los ítems se relaten desde lo fallido (debut sexual no consumado, devoción a un escritor que no le corresponde, falta de experiencia con las drogas ${ }^{7}$ ), y se destaque la no adecuación entre la experiencia vivida y lo esperado socialmente, lo que va configurando una imagen paradójica de perdedor-ganador que pone en crisis la idea del ethos del autobiógrafo que señala Ricoeur (2006) como característica del género, la narración construye "una vida", con una idea de sucesión, encadenamiento de hechos, evolución profesional y subjetiva.

17 Más allá de la existencia indudable del efecto enrarecido que la presentación antiheroica del yo produce, con esos momentos en que no se sabe si quien narra está ironizando o no, resulta consistente con ella la opción por el realismo estético y el tono tradicional de la autobiografía. Esta opción estética es narrada en el capítulo "Por qué escribo tan buenos poemas" a partir de una anécdota de iniciación en la que el futuro 
escritor, en su adolescencia, gana un concurso de poesía con un texto de "poesía social", cuyo tema ha sido elegido azarosamente. Se refuerza hacia el final del capítulo cuando afirma, ya sin el humor que permeaba la anécdota, "empecé a conocer sistemáticamente la poesía argentina contemporánea y me hice furiosamente realista" (2010: 42); para alcanzar su punto más alto en dos afirmaciones: "el único valor que le concedo a la literatura es el de ser verdadera" (26), y "Helder me enseñó que la poesía es demasiado exigente para permitir cualquier servilismo a la basura biográfica o psicológica (por eso elijo un medio subalterno, la prosa narrativa, para hablar de mí)" (43). Esto permite pensar la escritura de la autobiografía podrida como un elemento más de la poética de Rubio: la exposición del yo, en el espacio narrativo autobiográfico, confirma la apuesta de la poesía realista de los 90, su relación con el objeto y con el lenguaje, como exterioridad absoluta respecto del sujeto y la emoción, como construcción verbal autónoma, y en franca oposición a la versión corriente de lo poético escolar (léase, las secuelas indeseables de un romanticismo mal entendido que asocia poesía con subjetividad y sentimiento).

El yo del escritor de la autobiografía tradicional, entonces, cuadra bien teóricamente con esta posición, como una concepción del sujeto dueño del lenguaje, de la representación y de la autorepresentación; hasta el último capítulo, momento en que se produce un quiebre, y los personajes y locaciones del texto comienzan a fragmentarse, como respondiendo a la mirada en "la columna espejada" que centra la atención del narrador. La descripción se vuelve un poco más metafórica e inverosímil. Allí se cierra el libro relatando su comienzo de escritura: "se me presentó mi historia, íntegra y segmento a segmento, con sus hechos destacados, su nulidad y su atmósfera. Sin empatía y sin rechazo la contemplé pensando: esto es lo que me pasó, esto es lo que hice, éste soy yo" (56).

19 No obstante presentar una clara "orientación hacia la verdad" (Pozuelo Yvancos 2004) Rubio construye, prolijo y en pocas páginas, la imagen de un poeta de los 90: discípulo de Helder, peronista, reivindica a Leónidas Lamborghini y pasea por Belleza y Felicidad, después de citar a Gambarotta. Si según Panesi, "todo lo que se afirma en la autobiografía de escritores tiene que ver con el título de un capítulo de Ecce Homo: "Por qué escribo tan buenos libros"" (2006: 67), este es exactamente el título de uno de los capítulos de Rubio, quien parece instalarse cómodamente en ese lugar de autor. “Qué otros géneros, entonces, podrían cumplir mejor con el mandato democrático moderno ligado tanto a la verdad como a la subjetividad en tanto presuntas plenitudes, sino la biografía, la confesión y el diario íntimo, ahí donde un sujeto pretende una completud que sabe que no tiene?", preguntaba Panesi (2010: 69). Lugar imaginario entonces de esa completud anhelada, de esa historia que hace de la vida y del yo una inteligibilidad y una unidad (Ricoeur 2006), la autobiografía le permite a Rubio reunir sus fragmentos para rubricar una carrera literaria.

El ciclo parece cerrado, y la literatura es, para Rubio, una forma de hacerse un nombre, de reunir la identidad en una ficción fuerte. Yo, Alejandro Rubio, poeta premiado de los 90, explico cómo me hice poeta y por qué escribí tan buenos poemas, o no, o sólo finjo hacerlo, en las reglas del género que así lo permite, no sin humor. Remata la historia de su vida con un final abierto (si la vida no termina el libro tampoco puede terminar) y auto-irónico: "Ahora que me acerco al punto final, dudo si he logrado transmitir lo extraordinario que fui para mí, en el recuerdo" (2010: 58). Punto máximo de la postura nihilista que no adjudica valor ni relevancia a nada, como no sea a título privado, la 
autobiografía cierra sobre la confirmación de su inutilidad y la duda sobre su capacidad de converger con la verdad, y deja al lector tan solo como al autor. No obstante, en el recorrido, una ficción narrada, la de un poeta de los 90 llamado Alejandro Rubio, ha sabido conjurar y hacer aparecer lo real, y triunfa al mismo tiempo que proclama su fracaso ${ }^{8}$.

\section{Silvio Mattoni}

Muy diferente es el sujeto de la enunciación, y aún del enunciado, que se construye en los diarios de Mattoni que se leen tanto en Campus (2014), como en los fragmentos que acompañan Tanatocresis (2018). Campus es un diario conformado por entradas sin consignación de fechas ni número de página; salió como libro objeto, con grabados y encuadernado artesanalmente, en una tirada de cincuenta ejemplares numerados, y se reeditó en 2016, con paginación; Tanatocresis reúne poemas y algunas entradas del diario que le son contemporáneas, también sin fecha. La diferencia respecto de la narración autobiográfica en este registro diarístico no se da sólo porque la escritura de lo diario, con su ritmo y sus leyes del género, su atención al presente, evita las totalidades, y lo narrativo, con su armazón temporal, su búsqueda de sentido más o menos unitario y el esquema de causas y consecuencias - como razón de una vida o "reconstitución y desciframiento de una vida en su conjunto" (Gusdorf 1991: 13)-, sino porque se sitúa en la dimensión de la gratuidad absoluta: manera de pasar el tiempo, o de ocuparlo, resto de escritura que surge cuando no salen las cuentas del metro del poema, o cuando se está cansado, o se espera algo (que una hija salga de una clase, que se haga la hora de entrar a una reunión). La escritura del diario tampoco recoge bocetos para poemas, experimentaciones o borradores, aunque pueda establecerse una relación entre ciertos hechos y reflexiones de la escritura diarística con los poemas ${ }^{9}$.

Es tal vez en la limitación del diario a su falta de pretensión, y su ubicación en una especie de presente absoluto, en las que radica, se podría decir, tanto la profundidad de superficie (si se hace valer este oxímoron, que remite a la superficialidad como escritura del instante, sin ulteriorización, pero a la profundidad en la medida en que esa entronización del instante y de lo intrascendente se vuelve una ética, una poética y una filosofía) que la hace llegar a la esencia del género, esto es, la pura ausencia temática y enunciativa; como lo que la conecta con la poesía en tanto género y le da una dimensión literaria.

Es también el motor de la escritura, es decir, es lo que funciona como ideal de la escritura diarística de Mattoni. Dice al comienzo de Campus: “ipodré hacer una prosa que no trate de nada y donde no perciba los acentos?" 10 . Prosa sin prospección ni retrospección, escritura sin forma y sin proyecto, ocurrencias y frases de alguien a quien no le pasa casi nada, la falta de pretensión es la condición de inicio del trabajo de la escritura, y se hace notoria también en los materiales que utiliza: se escribe en una libreta comprada "en el museo de un artista algo impostado y con una birome estándar con el logo para incautos". Contra la impostación entonces, contra la firma de lo que se rubrica como mercancía (la firma del artista o del autor fetichizada), cautamente, la escritura se despliega como escritura sobre nada que se quisiera de nadie.

Mattoni escribe sobre un fondo de nada, escribe la nada, porque esos son los puntos reversibles de una ecuación: lo que hay, siempre -es la única certeza- es la escritura y es la nada (ningún sentido trascendental, ningún fin, tal vez, incluso, nada que decir), 
que como extremos polares, se tocan, se revierten, como se tocan todo el tiempo, en su escritura, la vida y la muerte.

Son evidentes los ecos de la gran frase de Flaubert ${ }^{11}$. Sin embargo, si pueden observarse las huellas de las largas lecturas, de los trabajos de traducción, de los ensayos escritos, en los poemas y el diario íntimo de Mattoni, es porque la subjetividad es un entrepalabras, y el resultado no es la estetización soberbia de fines del XIX; es la mirada derrotada de fines del XX y principios del XXI que tantea el espacio alrededor y el espacio interior para buscar algo que ya sabe que no está ahí y que no va a estar ahí.

Por eso habla todo el tiempo, en Campus, y como quien no quiere, de lo que más interesa, de aquello que concernía tan bien a Flaubert y que Flaubert supo también como después lo supo Sartre aunque de mejor modo: el sinsentido de sostener toda una vida sobre el trabajo de la escritura. Esto podría remitirnos también a Kafka y su diario discurrir. Sin embargo aquí el desgarramiento es mínimo, si lo hay. En rigor, todo o casi todo es mínimo de algún modo. La pobreza de la escena y su reiteración, la verdadera catástrofe íntima que Silvio Mattoni persigue y cela desde los inicios de su trabajo de escritura, desde los primeros poemas, se vuelve entonces no remedo de una vida sino la vida misma: pulsación, respiración, ritmo. Eso es el diario: pequeñas notas breves que se suceden, con una estructura mínima, de cuño proustiano. Una somera anotación sensorial, referida las más de las veces a una observación sobre los efectos del clima o la estación en las especies arbóreas, florales o el cielo mismo del campus, seguida de una asociación a ideas o emociones también mínimas, eso del lado del paisaje exterior. A continuación una observación sobre el paisaje que se divisa en un interior particular: la mesa de un bar, que no es siempre el mismo, o la línea de mesas de lectura de la biblioteca. Allí un sujeto escribe en su diario sus observaciones diarias sobre, entre otras cosas, el diario, pero también sobre la fugacidad de lo que lo rodea, de la belleza entrevista al pasar de un paisaje interior siempre cambiante, el bar y las estudiantes, algunas profesoras que pasan no menos leves que pájaros que recorrieran el paisaje exterior, y el tampoco menos leve deslizarse de la bolita de una birome hecha en china sobre un cuadernito cartonero.

El tiempo pasa así, es una escritura de espera que es a la vez la vida misma como acontecer puro, o incluso, hacia los últimos cuadernos, prefiguración o prognosis: el libro que vendrá, el de la vida diaria "real", con su sucesión de clases y reuniones y exámenes que se renueva cada año, envejecido. Un transcurrir realzado en todos sus detalles: no hay anotación alguna de fecha, con lo que se subvierte la regla principal del diario, no hay nombres, sólo algunos perfiles de personajes que se dejan adivinar con dulzura y que no son un guiño al lector. Si como lo define Gracia (2004: 230) en última instancia, es el yo diluido en los fragmentos diarísticos, el que preside el desarrollo del diario, más allá de los cortes temporales y la intimidad que constituyen las reflexiones personales de los sucesos acontecidos a lo largo del día, este reconoce la importancia de una acción y, sobre todo, unos personajes secundarios derivados de la trama que protagoniza el yo. Sin embargo estos últimos elementos también se diluyen en una escritura que da cuenta de momentos de soledad y evita los nombres de personas, fechas y lugares, y la determinación de contextos precisos.

Pero esta escritura es también un registro. ¿Registro de qué? De algo menos que una vida: "no se trata de amor ni sentimientos ni relatos, sino de impactos, impresiones, choques" (Mattoni 2014). Escritura del instante, escritura polaroid, podríamos decir, no lleva el gesto de lo espontáneo o ingenuo de una vanguardia, dado que sabe de las 
distancias entre la vida y la letra. "No pretendo escribir este momento", dice, "pero sí registrarlo" (2014), porque la distancia entre el momento y la escritura del momento sería infranqueable, como es infranqueable la distancia que existe entre la palabra y la cosa. Sin embargo la escritura no conlleva una vanidad que la anularía, no es fútil si se logra "sostener la imagen encantada de una impresión fugaz" (2014), duplicar la fugacidad del instante con la de la escritura. Lo diarístico da lugar al registro de eso que se es, un sujeto que lee y escribe, y se define así: "soy un continuo de frases discontinuas" (2014). La instancia de sujeto que atenta también contra la idea de lo autobiográfico como prosopopeya extendida (de Man 1991) o como construcción de identidad (Castilla del Pino 1996) ${ }^{12}$, si no se reduce la prosopopeya y aun la identidad del individuo a un cruce particular de frases oídas, textos repetidos, historias narradas por otros o por sí mismo, de escasa importancia.

Cuando la materia de la que está hecho el sujeto son las palabras, la escritura es una actividad incansable y el acto de escribir es consustancial al de vivir: como en ese cuadro de Escher en que la mano, duplicada, se dibuja dibujándose, la escritura del momento es el momento mismo de la escritura. Entonces entre la palabra y la cosa, la distancia se recorre de ida y de vuelta sin tragedia, no hay desgarro o doblez: se es las palabras, los textos que se han leído, las voces que regresan de los amigos muertos (y constituyen la extensa elegía que es Tanatocresis), las letras de las canciones que se escuchan; se es en la escritura de los acontecimientos mínimos de la percepción de cada día, en esas palabras que al registrarlos los realizan como acontecimientos. En esa dimensión la literatura es la vida misma porque la literatura se define como una intimidad con la palabra; la literatura es esa "experiencia en la que algo íntimo e inexpresable pugna por ser dicho" (Giordano 2008:11).

En Mattoni lo autobiográfico, la remisión a sí mismo y a las pequeñas escenas de la vida cotidiana, si bien reconocibles, tienen un sello proustiano en la medida en que no ingresan al texto sino como unidades materiales de una poética recursiva. Se trata de un trabajo de expansión, desde un pequeño núcleo, de una aventura que es a la vez sensorial, conceptual, y afectiva (no en el sentido de sentimental sino del afecto como aquello capaz de ejercer un impacto sobre el sujeto a un nivel específico que lo configura al mismo tiempo como experiencia estética y como vivencia). El yo que enuncia no permite nunca que se constituya un sujeto pleno, sujeto que sería portavoz del enunciado y sujeto de la enunciación, amo de su querer decir, sino que en el juego del poema y del diario no abandona nunca su estatuto de inconsistencia productiva, de duda, de repliegue reflexivo sobre sí, sobre los otros, sobre los objetos, sucesos, acontecimientos, paisajes, que lo rodean. Se trata de una escritura transida de lo que ya había dicho Mattoni en su traducción de Deleuze: "La literatura no se instala más que descubriendo bajo las aparentes personas la potencia de un impersonal que no es de ninguna manera una generalidad, sino una singularidad en un punto más alto: un hombre, una mujer, una bestia, un vientre, un niño..." (Deleuze 2006: 15) ${ }^{13}$.

31 Aunque se diga cada tanto que nada equipara al hecho de tener entre las manos la mano chiquita de un hijo, o a la belleza móvil de una joven estudiante que se inclina sobre un libro, abstraída en sí misma, la literatura, la escritura, la percepción, arman un continuo, como una masa cuyas intensidades y cantidades se distribuyen de manera discreta (Mallol 2016). Para la poesía, un ritmo, ese ritmo que "es el ministro del tiempo continuo" (Mattoni 2018: 77), para la prosa un flujo; en todo caso, siempre, la escritura como forma de vida. 
Porque "no hay sentido, claro, pero qué intenso puede ser el instante" (2014) dice, y construye en palabras un don intenso para el lector: sucesión de palabras y sucesión de momentos, un continuo material que se opone pero complementa con los tiempos ritmados y cortados de los endecasílabos de su poesía y las pausas de fin de verso, para hacer de la literatura y de la vida una cuestión de ritmo, de respiración, de medida de la sustancia lingüística y sus posibilidades combinatorias, distributivas, como ejecuciones musicales de intensidades variables.

Cada tanto, como una punta de alfiler, la disyuntiva entre la vida y la poesía asoma, para diluirse en el mismo flujo de la palabra, la sucesión, los sentidos, las imágenes y la imaginación, como cuando dice "mientras escribo, pasa la vida, pero es imperceptible como un sueño olvidado" (2014). Lo imperceptible entonces es la vida, pero también el estilo: quiere volverse impersonal, borrar las huellas de una vida como acontecimiento singular remarcable, evitando las marcas que otros escritores se esfuerzan en construir (los diminutivos de Carrera, los neologismos de Gelman, las imágenes de Pizarnik, el vocabulario realista de sus contemporáneos) para dejar que brille, en la frase siempre gramaticalmente bien construida, el ritmo de los versos o la ritmicidad de la prosa. Ese estilo construido a base de sobriedad será entonces el escalón que permita el advenimiento de lo escrito como registro de haecceidades. "Una estación, un invierno, un verano, una hora, una fecha, tienen una individualidad perfecta y que no carece de nada, aunque no se confunda con la de una cosa o sujeto. Son haecceidades, en el sentido de que en ellas todo es relación de movimiento y de reposo entre moléculas o partículas, poder de afectar y de ser afectado" ${ }^{14}$, dicen Deleuze y Guattari (2006: 264). Si estas haecceidades ${ }^{15}$ son lo que corta la estructura de la narración en Flaubert, hasta casi hacerla estallar en Joyce, Proust y Woolf, Mattoni hace de ellas la materia misma del diario.

\section{Conclusiones}

Dicen los biólogos que el comensalismo es una forma de interacción biológica en la que uno de los intervinientes obtiene un beneficio, mientras que el otro no se perjudica ni se beneficia. Metabiosis o tanatocresia (del griego Oávaros [thánatos], 'muerte'): consiste en el aprovechamiento que realiza una especie de restos, excrementos, esqueletos o cadáveres de otra especie con el fin de protegerse o de servirse de ellos como herramientas. Ejemplos son los cangrejos ermitaños o Pagurus, que protegen su blando abdomen introduciéndose en la concha vacía de un caracol, y el pájaro Camarhynchus pallidus, de las islas Galápagos, que utiliza una espina de cacto para extraer los insectos de los agujeros. Se trata de un beneficio trófico, de una ganancia sin maldad ni desprecio, sin expoliación ni violencia.

Uno podría pensar que los diarios serían esto para los poetas, reservorio de materiales para poemas futuros. Que las autobiografías serían, o podrían ser, a la inversa, reconstrucciones del yo autoral que se comenzaba a delinear en los textos poéticos. Pero no es así en estos casos, o en otros que aparecen contemporáneamente (Inés Acevedo, Marcelo Matthey, Carlos Battilana).

Si Rubio plantea una disyuntiva excluyente (la poesía, rigurosa y exigente, por fuera de la excrecencia de la vida, y la prosa realista como lugar donde alojar los restos biográficos, lo que impide toda comunicación entre uno y otro género) lo que hay en Mattoni es una relación de equivalencia, de ida y vuelta, o una tanatocresis de doble 
sentido, entre el diario y la poesía, entre la escritura y la vida: cada una se aloja en la otra, a su manera.

La escritura aparece como un gesto que demora un poco la partida definitiva, del que escribe, de su vida, su familia, sus amigos, pero al mismo tiempo inscribe al yo en la línea de lo que tiene que desaparecer, sin pathos trágico sino, al contrario, con un gesto autoirónico en Rubio y jovial en Mattoni.

En los poemas de Mattoni destaca el ejercicio de una voz inmaterial que sopesa las cuestiones con una distancia que es casi desapego a pesar de muchas remisiones autobiográficas, mientras deja, en el tono frecuentemente cercano a la elegía, su sello único: una poética grave y ligera. "Y aunque seamos un ruido entre dos nadas / que al menos tenga un juego, una alegría / o una angustia expresivas" (2018: 42), dice en un poema, y ubica, como única posibilidad de sentido, el juego con las palabras, la manifestación de una vida que pasa, para recordar "que esta vida es la única, y que el cielo llueve sin ninguna consonancia con el llanto" (2018: 87) porque "las palabras parecen decir que tenemos una vida, pero no más que Hécuba, y dura lo que demora el tiempo en disolver el cuerpo, en borrar los detalles que no fueron escritos" (2018: 99).

Lejos de efusiones descarnadas, o minucia vivida, nos encontramos con el mismo ejercicio de prestidigitación que habla y calla al mismo tiempo para exponer, en el teatro de voces, la matriz de un pensamiento que subraya lo que se deteriora y atenta contra lo bello, lo armonioso, lo amable, del lado del realismo sucio de Rubio, y lo que se esfuma sin llamar la atención, del lado de Mattoni, pero, aunque descrea de todo, se confirma en el trazo de la palabra sobre la hoja.

Ambos trabajando, cada uno a su manera, contra la construcción de un sujeto pleno, o de una historia narrada para la posteridad, la sucesión de momentos, y su escritura, "adivina la forma de la insignificancia" (Mattoni 2018: 92) o una la ubica como disolución ab initio de toda experiencia posible, insta al carpe diem en Mattoni, se ríe un poco por lo bajo en Rubio, se entrega a la vida, deja trazos, también efímeros, le arranca al vacío un par de frases, y afirma el trabajo de escritura.

41 En Rubio la afirmación misma está desencantada o degradada desde el comienzo. En Mattoni la posición es más epicúrea que cínica:

Y si tiene que ser una máscara, hecha de relieves o recuerdos falsos, acribillada de huecos para representar la masa amorfa, negra, del olvido, que al menos sea una expresión jovial, aunque no del todo cómica; que por el agujero destinado a la boca puedan salir repiqueteos, tarareos, algo más que las ideas comunes (...)”. (2018: 82)

La vida, la muerte, la poesía, dicen, están hechas de estas cosas: las charlas entre amigos, las ausencias, los recuerdos, la insistencia en vivir el momento. La escritura es esta conversación infinita. Rubio la afirma como el libro que, aunque no sepa si alcanza su objeto, no puede terminar mientras dure la vida, mientras que Mattoni nos hace partícipes de esa fulguración del instante, que ilumina un poco la materia de este mundo, diario o poema y afirma: "prendo / un bichito de luz antes de que amanezca / y el día opaque su indeciso fulgor" (2018: 44-45).

No se trata sin embargo en ningún caso de afirmar un pantextualismo del mundo como libro o la vida como continuo sígnico, nunca se pierde la consciencia acerca de la distancia que media entre lo que es lenguaje y lo que no lo es. Si el gesto de la escritura y de la lectura parecieran decir: el lenguaje lo es todo; la escritura y la lectura dicen el lenguaje no es nada. Pero no habría vida posible para estos sujetos sin el lenguaje, y no habría lenguaje posible sin una vida que lo trascendiera. La mano se estira en el 
lenguaje para tocar un cuerpo que sabe que no podrá alcanzar, el lenguaje se tensa para hacer algo perdurable de ese momento. No habría uno sin el otro, tanatocresis o cinta de Moebius, no habría uno sin el fracaso del otro.

\section{BIBLIOGRAFÍA}

Castilla del Pino, Carlos, “Teoría de la intimidad”, Revista de Occidente, no 182-183, 1996, Madrid, p. 15-31.

Deleuze, Gilles, La literatura y la vida, Córdoba, Alción, 2006. Traducción de Silvio Mattoni.

Deleuze, Gilles y Guattari, Félix, Mil mesetas. Valencia, Pretextos, 1994.

De Man, Paul, “La autobiografía como desfiguración”, Suplementos. Estudios e investigación documental, n²9: "La autobiografía y sus problemas teóricos”, 1991, Barcelona, Anthropos, p. 113-117.

Flaubert, Gustave, Cartas a Louise Colet, Madrid, Siruela, 1999. Traducción de Ignacio Malaxecheverría.

Giordano, Alberto, El giro autobiográfico, Buenos Aires, Mansalva, 2008.

Gracia, Jordi, “La voz literaria y la materia del diarista”, en Hermosilla Álvarez, M. A., Fernández Prieto, C., Autobiografía en España, un balance, Madrid, Visor, 2004, p. 223-234.

Gusdorf, Georges, "Condiciones y límites de la autobiografía”, Suplementos. Estudios e investigación documental, n²9: "La autobiografía y sus problemas teóricos", 1991, Barcelona, Anthropos, p. 9-17.

Lacan, Jacques, Seminario XI: Los cuatro conceptos fundamentales del psicoanálisis, Buenos Aires, Paidós, 2008.

Lejeune, Philippe. "El pacto autobiográfico", Suplementos. Estudios e investigación documental, n²9: "La autobiografía y sus problemas teóricos", 1991, Barcelona, Anthropos, p. 47-61.

Loureiro, Angel (1991). "Problemas teóricos de la autobiografía", Suplementos. Estudiose investigación documental, n²9: "La autobiografía y sus problemas teóricos”, 1991, Barcelona, Anthropos, pp 2-8.

Mallol, Anahí. "Poesía y autobiografía en Silvio Mattoni”, Actas del VI Coloquio Literatura y Vida, Universidad Nacional de Rosario, 2016, Web. Consultado el 07/12/2020.

Mattoni, Silvio, Campus, La Plata, Estructura mental a las estrellas, 2014 y La Plata, Eme, 2016.

Mattoni, Silvio, Tanatocresis, Córdoba, Borde perdido, 2018.

Minc, Joseph, La extraordinaria historia de mi vida ordinaria, Buenos Aires, de la Flor, 2009.

Panesi, Jorge, "El precio de la autobiografía: Jacques Derrida, el circunciso", Orbis Tertius, vol. 1, nº 1, La Plata, Universidad Nacional de La Plata, p. 65-78.

Pastormerlo, Sergio, Borges crítico, Buenos Aires, Fondo de Cultura Económica, 2007.

Pizarnik, Alejandra, Obras completas, Buenos Aires, Corregidor, 1994. 
---, Diarios, Barcelona, Lumen, 2005.

Rubio, Alejandro. “Autobiografía podrida”, La garchofa esmeralda, Buenos Aires, Mansalva, 2010, p 7-58.

Ricoeur, Paul, "La vida: un relato en busca de un narrador”, Ágora: Papeles de filosofía, no 25, 2006, Santiago de Compostela, Universidad de Santiago de Compostela, p. 9-22.

Pozuelo Yvancos, José María, “Autobiografía: del tropo al acto de Lenguaje”, Autobiografía en España, un balance, Madrid, Visor, 2004, p. 173-182.

\section{NOTAS}

1. No se trata de que sean menos problemáticas en el caso de la ficción, pero es evidente que éstas poseen un respaldo teórico y pragmático que hace que en general la crítica, y los escritores, se sientan eximidos de plantearlas

2. Nos referiremos en general a las escrituras del yo, para pasar más adelante a analizar dos obras, una autobiografía y un diario, momento en que señalaremos sus diferencias.

3. Las acusaciones al género desde la posmodernidad serán también previsibles y las ha hecho, entre otros, Foucault: restitución de la figura tradicional del autor, concepción trascendente y religiosa de la escritura, justificación del comentario incesante y de la interpretación: ¿restitución de la "vida"?

4. Por el momento no profundizaremos en las diferencias entre los subgéneros, dado que a este nivel las preguntas de base son casi las mismas. Más adelante se impondrá tener en cuenta algunas diferencias.

5. Intermedias, acá, y excepcionales, las Antimemorias de Malraux, a caballo entre la literatura, la aventura "novelesca", y la política.

6. Habría que pensar también los diarios del filósofo, del "teórico literario" o los del profesor.

7. “Tengo que confesar algo inconfesable: nunca me drogué" (2010:34).

8. Este fracaso de lo literario en la autobiografía la pone en el mismo clima de descreimiento con el que se ha caracterizado la poesía de los 90 y armoniza con la figura del poeta antiheroico que el texto mismo construye.

9. Esto es más claro en Tanatocresis. Allí se puede ver, excepcionalmente, una entrada que cuenta la historia de la tortuga que el narrador tuvo de niño, en las páginas 94-95, en tanto en las páginas 58 a 61 se lee un poema sobre el mismo tema. Dejamos para otra ocasión el análisis de las correspondencias y diferencias en el tratamiento del mismo en los distintos géneros literarios.

10. Citaremos de acuerdo con la primera edición de Campus, sin numeración de página, ya que esta elección editorial nos parece sustancial respecto de la poética de Mattoni en tanto hace a la idea de continuum.

11. En una carta fechada el 16 de enero de 1852, Flaubert le resume a Louise Colet su programa estético: "Lo que me parece hermoso, lo que querría hacer, es un libro sobre nada, un libro sin ataduras exteriores, que se aguantase a sí mismo con la fuerza interna de su estilo, como la Tierra, sin que la sostengan, se sostiene en el aire; un libro que casi no tendría argumento, o al menos donde el argumento fuera casi invisible, si puede ser" (1999: 165, trad. de Ignacio Malaxecheverría). ["Ce qui me semble beau, ce que je voudrais faire, c'est un livre sur rien, un livre sans attache extérieure, qui se tiendrait de lui-même par la force interne de son style, comme la terre sans être soutenue se tient en l'air, un livre qui n'aurait presque pas de sujet ou du moins où le sujet serait presque invisible, si cela se peut."]

12. Dice Castilla del Pino, refiriéndose a la constitución subjetiva de los géneros autobiográficos: "El proceso de construcción y desarrollo de un yo es análogo al de una narración, y posee, en 
efecto, una estructura narrativa: texto y tema, este último con introducción, desarrollo y final del argumento. (...) Cada yo, para utilizar una metáfora, es una película del sujeto" (1996: 31). Nada de esto puede encontrarse en Mattoni.

13. "[La littérature ] ne ne se pose qu'en découvrant sous les apparentes personnes la puissance d'un impersonnel qui n'est nullement une généralité, mais une singularité au plus haut point : un homme, une femme, une bête, un ventre, un enfant..."

14. "Une saison, un hiver, un été, une heure, une date ont une individualité parfaite et qui ne manque de rien, bien qu'elle ne se confonde pas avec celle d'une chose ou d'un sujet. Ce sont des heccéités, en ce sens que tout y est rapport de mouvement et de repos entre molécules ou particules, pouvoir d'affecter et d'être affecté."

15. Son, al mismo tiempo, reductos de lo poético, y aún de la lírica, como lo ha hecho notar Saer y lo ha practicado en los poemas de El arte de narrar.

\section{RESÚMENES}

El trabajo analiza los diarios de Silvio Mattoni y la autobiografía de Alejandro Rubio, dos poetas argentinos de los años noventa, en relación con sus visiones poéticas. Desde el marco de las teorizaciones recientes en torno a las escrituras del yo, el texto muestra de qué modo estos autores traman su relación con el género, e inscriben en él una impronta personal, que da su propia versión a la aparente aporía existente entre literatura y vida.

Ce travail analyse les journaux intimes de Silvio Mattoni et l'autobiographie d'Alejandro Rubio, deux poètes argentins des années 1990, par rapport à leurs visions poétiques. Dans le cadre des théories récentes sur les écrits du moi, le texte montre comment ces auteurs tissent leur rapport au genre, et y inscrivent une empreinte personnelle, qui donne sa propre version à l'apparente aporie entre la littérature et la vie.

This paper analyses the diaries of Silvio Mattoni and the autobiography of Alejandro Rubio, two Argentinean poets of the 1990s, in relation to their poetic visions. Within the framework of recent theorizations about the writings of the self, the text shows how these authors weave their relationship with the genre, and inscribe a personal stamp on it, which gives its own version to the apparent aporia between literature and life.

\section{ÍNDICE}

Mots-clés: littérature, vie, journal intime, autobiographie, poètes

Keywords: literature, life, diary, autobiography, poets

Palabras claves: literatura, vida, diario, autobiografía, poetas 
AUTOR

ANAHÍ MALLOL

IDIHCS (CONICET-UNLP)-UNA

anahimallol@yahoo.com.ar 